\title{
Visco-elastic stress triggering model of Tangshan earthquake sequence
}

\author{
WAN Yong-ge ${ }^{1,2), `}$ (万永革) SHEN Zheng-kang ${ }^{3)}$ (沈正康) ZENG Yue-hua ${ }^{4)}$ (曾跃华) \\ SHENG Shu-zhong ${ }^{1)}$ (盛书中) XU Xiao-feng ${ }^{2}$ (徐晓枫) \\ 1) Institute of Disaster Prevention Science and Technology, Sanhe 065201, China \\ 2) Institute of Geophysics, China Earthquake Administration, Beijing 100081, China \\ 3) Department of Geophysics, Peking University, Beijing 100871, China \\ 4) U. S. Geology Survey, Golden, CO, 80401, USA
}

\begin{abstract}
We calculated the Coulomb failure stress change generated by the 1976 Tangshan earthquake that is projected onto the fault planes and slip directions of large subsequent aftershocks. Results of previous studies on the seismic failure distribution, crustal velocity and viscosity structures of the Tangshan earthquake are used as model constraints. Effects of the local pore fluid pressure and impact of soft medium near the fault are also considered. Our result shows that the subsequent Luanxian and Ninghe earthquakes occurred in the regions with a positive Coulomb failure stress produced by the Tangshan earthquake. To study the triggering effect of the Tangshan, Luanxian, and Ninghe earthquakes on the follow-up small earthquakes, we first evaluate the possible focal mechanisms of small earthquakes according to the regional stress field and co-seismic slip distributions derived from previous studies, assuming the amplitude of regional tectonic stress as $10 \mathrm{MPa}$. By projecting the stress changes generated by the above three earthquakes onto the possible fault planes and slip directions of small earthquakes, we find that the "butterfly" distribution pattern of increased Coulomb failure stress is consistent with the spatial distribution of follow-up earthquakes, and $95 \%$ of the aftershocks occurred in regions where Coulomb failure stresses increase, indicating that the former large earthquakes modulated occurrences of follow-up earthquakes in the Tangshan earthquake sequence. This result has some significance in rapid assessment of aftershock hazard after a large earthquake. If detailed failure distribution, seismogenic fault in the focal area and their slip features can be rapidly determined after a large earthquake, our algorithm can be used to predict the locations of large aftershocks.
\end{abstract}

Key words: Tangshan earthquake, stress triggering, viscoelasticity, stress direction

CLC number: P315.72 7 Document code: A

\section{Introduction}

The July 28, 1976 Tangshan earthquake is one of the most catastrophic events in history (QIU, 1976). The following Luanxian $M_{\mathrm{S}} 7.1$ aftershcok, which occurred about 15 hours later, made the disaster more serious. Ninghe $M_{\mathrm{S}} 6.9$ earthquake occurred in the southern part of the fault on November 15 of the same year. A large number of aftershocks have been occurring continuously up to the present. What is the relationship between the mainshock and the aftershocks of Luanxian and Ninghe? What is the relationship between the above three earthquakes and the fol-

\footnotetext{
* Received 2008-03-06; accepted in revised form 2008-09-25.

Foundation item: National Natural Science Foundation of China (40374012 and 40874022).

*Author for correspondence: wanyg217217@vip.sina.com.cn
} 
lowing aftershocks? The study on these questions will provide a better understanding of the interaction between large earthquakes and that between mainshock and aftershocks, which will have a certain practical significance for seismic hazard assessment.

In recent years, the study on effects of Coulomb failure stress change produced by large earthquake on the location and occurrence time of the follow-up earthquakes has attracted wide attention in the international seismological circles (Harris, 1998; Stein, 1999). Many case studies show that the increase of Coulomb failure stress encourages the occurrence of the follow-up moderate-strong earthquakes in the earthquake sequence (Troise et al, 1998; Robinson and ZHOU, 2005) and has certain influence on their aftershock activity (Das and Scholz, 1981; Toda et al, 1998; MA and CHAN, 2005). This provides a new way to assess the hazard of the aftershocks.

The previous studies on seismic stress triggering effect were mostly based upon the simulation of elastic deformation (Okada, 1992), so only elastic response of stress change can be estimated. This is a better approximation for stress and strain field in a relatively short time period after an earthquake. But for a longer interval (i.e., decades period), the long-term stress change caused by visco-elastic relaxation of the media can not be ignored. This visco-elastic relaxation effect is due to the coupling between the brittle upper crust and the visco-elastic lower crust and upper mantle (Nur and Mavko, 1974; Rydelek and Sacks, 1990). Pollitz's (1992) study has shown that the co-seismic deformation is greater than that of the post-seismic in near-field, but in the far field region which is several times of the elastic thickness away, and in a time period of several times of the media characteristic time, the post-seismic deformation is much larger than the co-seismic deformation. For example, it has been found that, the 1995 M7.0 Kobe, Japan, earthquake was advanced by stress relaxation produced by two $M 8$ large earthquakes several hundreds of kilometers away in the Nanhai Trough in 1944 and 1946 (Pollitz and Sacks, 1997). Using a visco-elastic model, Ben-zion et al (1993) also concluded that the Parkfield earthquake was modulated by visco-elastic stress transfer produced by the 1857 Fort Tejon earthquake occurred on the San Andreas fault. They gave the time of next big earthquake is $1992 \pm 9$ years, and Parkfield earthquake occurred in 1994. The occurrence of the $1999 M_{\mathrm{w}} 7.0$ Hector Mine, California, earthquake is particularly interesting because it took place only about $20 \mathrm{~km}$ away from and 7 years after the $1992 M_{\mathrm{w}} 7.3$ Landers earthquake. The closeness in space and time leaves little doubt of their causality. Using the earthquake source model by Wald and Heaton (1994) and the crustal model of elastic half-space, scientists from US Geological Survey et al (2000) calculated the static Coulomb failure stress change at the epicenter of the Hector Mine earthquake imposed by the rupture of the Landers earthquake. And the result shows that although the normal stress change seemed to have unlocked the Hector Mine seismogenic fault, the overall Coulomb failure stress change on the fault was negative. It means that the co-seismic stress change cannot satisfactorily explain the triggering effect of the Landers earthquake on the Hector Mine earthquakes. Using respectively a 3-D finite element code and a generalized reflection/transmission matrix method, Freed and LIN (2001) and ZENG (2001) estimated Coulomb failure stress change generated by a viscous lower crust and upper mantle. They found that post-seismic Coulomb stress increase by 0.1 0.2 MPa at the epicenter of the Hector Mine earthquake seven years after the Landers earthquake, which finally triggered the Hector Mine event. Considering inter-seismic strain accumulation, visco-elastic relaxation and stress change caused by earthquakes, WAN et al (2007) and Pollitz and Schwartz (2008) verified the good corresponding relationship between stress transfer and subsequent earthquake occurrences in northeast Qinghai-Tibet plateau and San Francisco bay region respectively. All these results suggest the importance of considering visco-elastic relaxation 
process in evaluating the stress transfer and earthquake triggering process, and eventually in assessing seismic hazard potential.

This paper aims to study the stress triggering in Tangshan earthquake sequence. For this problem, WAN et al (2000) has studied Coulomb failure stress change projected on fault plane and slip direction generated by Tangshan mainshock by using simple failure model. They found that the Tangshan mainshock had triggering effect on the occurrence of Luanxian earthquake. Liu and FU (2000) have studied the elastic triggering effect of Tangshan mainshock with three segments slip model on aftershocks in the three regions. They found that the mainshock occurrence encouraged the follow-up earthquakes. Robinson and ZHOU (2005) have studied the stress interaction between fault segments of Tangshan mainshock and the triggering effect of mainshock on Luanxian and Ninghe earthquakes. They found that the initial ruptured southern fault segment encouraged the subsequent rupture in northern fault segment, and the occurrence of mainshock have triggering effect on the occurrence of follow-up Luanxian and Ninghe earthquake. But for the aftershock triggering in decades, the post-seismic visco-elastic relaxation effect cannot be ignored (SUN et al, 1994; SHEN et al, 2003; WAN et al, 2007b). In addition, studies have shown that the calculated surface deformation has large difference by adopting homogeneous visco-elastic model and layered visco-elastic model (e.g. LI et al, 2005). So it is necessary to use layered visco-elastic model in this study. In addition, pore pressure change in pore fluid migration caused by quarrying can explain the change of seismicity nearby (Seeber et al, 1998). Nur and Booker (1972) pointed out that the pore pressure change caused by mainshock could control the occurrence time of aftershocks. Piombo et al (2005), in their study on how the post-seismic pore fluid flow affects the Coulomb failure stress change, found that the post-seismic pore fluid flow not only changed the quantity of the Coulomb failure stress change but also changed the positive and negative of the Coulomb failure stress change in certain areas, $i$. e., converting the area that encourages earthquake occurrence into one that discourages earthquake occurrence, and vice versa. Taking 2005 Pakistan earthquake as example, WAN et al (2007a) explained the influence of Coulomb failure stress change caused by medium viscous relaxation and the change of pore pressure near the fault. So it is necessary to consider the influence of pore fluid pressure in calculating Coulomb failure stress change. This paper will focus on discussion of these problems and study on the triggering effect of mainshock on aftershocks based on tectonic stress state in study area.

\section{Focal parameters and crustal model}

\subsection{Focal parameters}

The Tangshan earthquake occurred at the northern margin of the North China plain where seismic activities are active. The regional tectonics is characterized by faulting along a NNE trending right-lateral strike-slip fault (Chen and Nabelek, 1988). A great number of studies have been done about the Tangshan earthquake. The strike of the mainshock fault plane was estimated $\mathrm{N} 20^{\circ} \sim 30^{\circ} \mathrm{E}$ from the studies of $\mathrm{P}$ wave first motion (ZHANG et al, 1980), P waveform fitting (Butler et al, 1979), and body wave inversion (ZHOU, 1985; Kikuchi and Kanamori, 1986; Nabelek et al, 1987), and $\mathrm{N} 40^{\circ} \mathrm{E}$ from the study of surface waveform fitting, and $\mathrm{N} 50^{\circ} \sim 60^{\circ} \mathrm{E}$ from geodetic data inversion (CHEN et al, 1979; ZHANG, 1982). These results reflect the complexity of the Tangshan seismic rupture and seem to suggest that the rupture started from the southern segment with the strike of $\mathrm{N} 20^{\circ} \sim 30^{\circ} \mathrm{E}$, and then propagated to the northern segment with the strike of $\mathrm{N} 50^{\circ} \sim 60^{\circ} \mathrm{E}$. The study on aftershock distribution also shows that the aftershock zone can 
be divided into two segments, the north and the south segments respectively (Shedlock et al, 1987). The strike of the south segment is $\mathrm{N} 30^{\circ} \mathrm{E}$, and the strike of north segment is $\mathrm{N} 50^{\circ} \sim 60^{\circ} \mathrm{E}$. The intersection of the faults is under the city of Tangshan. According to the vertical displacement data, the boundary between northwest uplifting and southeast settlement also has a surface trace with a strike of $55^{\circ}$ in north part of fault (ZHANG et al, 1980). XIE and YAO (1991) studied the results of Tangshan mainshock rupture mechanism synthetically and gave a rupture model with seven segments. They inverted the rupture process using body wave data and geodetic data (XIE and YAO, 1991). HUANG and Yeh (1997) also adopted a similar model in their finite element inversion by using geodetic data and gave the similar result with XIE and YAO (1991). However, these inversion results showed slight decline of the northwest plate, which cannot explain the observation with uplifting in northwest and settlement in southeast. WAN et al (2008) inverted the parameters of strike, dip and location of these fault planes by using the precise populated earthquakes from double difference method and seismic wave data recorded by Digital Seismic Network of Capital Area. According to direction and relative value of local stress field (XU, 1985), they also got the rake angle of each of the faults. Their model is more consistent with the direction of tectonic stress in study area. Although this model is different in dip direction with that of CHEN et al (1979), it also can explain the observation with uplift of the northwestern plate and settlement of the southeastern plate. Besides, by using the geodetic data, the model inverted by CHEN et al (1979) contained the aftershock effect, which is beneficial to study on the comprehensive effect of mainshock and aftershocks in short time but can not be used to study the influence of large aftershocks caused by mainshock. Considering WAN et al's model (WAN et al, 2008) can also be explained by geodetic data, we use the parameter of strike, dip, rake and location given by WAN et al (2008) to maintain the consistency of model selection. The slip values are calculated by using the seismic moment of two segments in main shock given by HUANG and Yeh (1997) (Table 1).

Table 1 Fault rupture parameters of Tangshan mainshock and its two large aftershocks (WAN et al, 2008; HUANG and Yeh, 1997)

\begin{tabular}{lcccccccccc}
\hline \multicolumn{1}{c}{ Earthquake } & Strike $^{\circ}$ & Dip/ & Rake $/{ }^{\circ}$ & Length $/ \mathrm{km}$ & Width $/ \mathrm{km}$ & Slip $/ \mathrm{m}$ & $\lambda_{\mathrm{E}} /{ }^{\circ}$ & $\varphi_{\mathrm{N}}{ }^{\circ}$ & $M_{\mathrm{S}}$ \\
\hline Mainshock & 1 & 233 & 89 & 172 & 35 & 15 & 2.89 & 118.34 & 39.68 & 7.8 \\
& 2 & 210 & 74 & 174 & 29 & 15 & 3.93 & 118.09 & 39.44 & \\
Luanxian & 92 & 37 & -90 & 17 & 16 & 1.56 & 118.66 & 39.81 & 7.1 \\
Ninghe & 299 & 61 & -25 & 20 & 16 & 0.62 & 118.88 & 39.45 & 6.9 \\
\hline
\end{tabular}

According to Nabelek et al (1987), Luanxian earthquake, which occurred in the northeast of Tangshan mainshock, is a normal fault with EW strike, but Huang and Yeh (1997) selected the north-dipping fault plane in their simulation, which cannot explain the settlement of south plate, so we selected the south-dipping fault plane, which is consistent with settlement of south plate. The fault plane of Ninghe earthquake, which located in the southwest of mainshock, is a left-lateral strike-slip fault with slightly normal component according to Nabelek et al (1987). Since no other restriction could be found, we use the fault parameters given by HUANG and Yeh (1997).

The fault parameters of Tangshan mainshock and two large aftershocks are listed in Table 1. According to the study of Shedlock et al (1987), the aftershocks occurred on faults are mostly within the depth of 7 22 km. The result is basically consistent with the depth of the fault plane inverted by using accurately located small earthquakes achieved by WAN et al (2008). So the top and width of fault are taken as $7 \mathrm{~km}$ and $15 \mathrm{~km}$ in this study.

Although there is no obvious foreshock for this earthquake, there occurred a lot of aftershocks 
in addition to the two above-mentioned large aftershocks. We collected all the aftershocks near the source from the time after Ninghe earthquake to September, 2005, deleted the earthquakes with zero depth which error may be bigger and drew the histogram of their depths (Figure 1). Great number of focal depths can be seen to be distributed within a depth range of 5 20 km. The average depth of the aftershocks is $12 \mathrm{~km}$. So we calculated Coulomb failure stress change at the depth of $12 \mathrm{~km}$ to study the triggering effect of the earthquakes on their aftershocks. In addition, in order to calculate the triggering effect of the earthquakes on their aftershocks, we need to know the direction of tectonic stress field near the source. By using focal mechanism of Tangshan aftershocks, XU and WANG (1986) achieved the direction of the compression stress axis is $N 60^{\circ} \mathrm{E}$ and that of the extension stress is $\mathrm{S} 30^{\circ} \mathrm{E}$, both horizontal, which is used in our study on the triggering effect of Tangshan mainshock and two large aftershocks on other aftershocks. Although the crust tectonic stress level is different with depth, we follow the simulation of the triggering effect of Landers earthquake on aftershocks by King et al (1994) and adopt tectonic stress level of $10 \mathrm{MPa}$ to calculate Coulomb failure stress change evolution at specific depth.

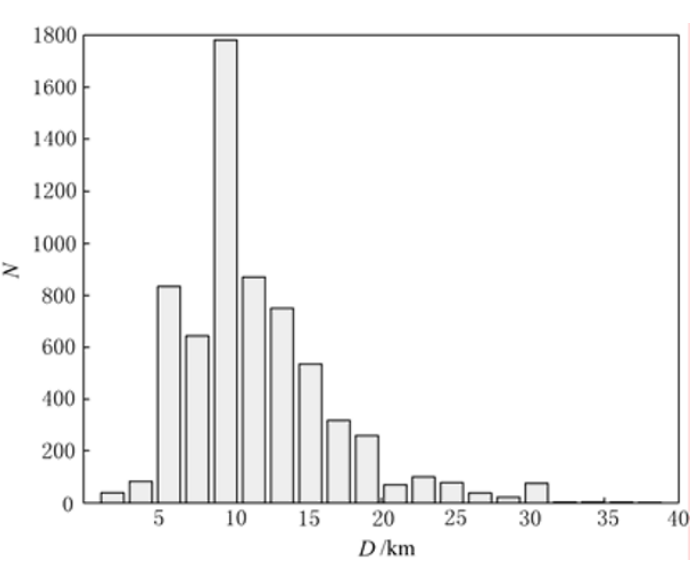

Figure 1 Depth distribution of aftershocks $N$ stands for earthquake frequency

\subsection{Crustal model}

The research of post-seismic deformation of Tangshan earthquake by LI et al (2005) shows large difference between the post-seismic deformation calculated in layered crustal medium and that in homogeneous elastic half-space medium. So it is necessary to study the interaction among earthquakes by using relatively accurate crustal model. By analyzing the seismic exploration results by LIU and JIA (1986), ZENG et al (1985) and inversion result by YU et al (2003), combining the velocity model under the seismic station by fitting the $\mathrm{P}$ wave and $\mathrm{S}$ digital seismic waveform by ZHANG et al (2001), we give the synthetic crust velocity model in Tangshan region (Table 2). The layered crustal density model, which was used in source process determination with near source seismic records by ZHENG and YAO (1993), is adopted in this study. The viscous structure of the North China plate inverted by using finite element method and co- and post- seismic horizontal and vertical deformation of Tangshan region in 1976 1985 given by SUN et al (1994) is also used in this study. We list the parameters of velocity, density and viscosity structure of crust in Table 2 with the profile of velocity and viscosity shown in Figure 2.

Table 2 Crustal structure parameters in this simulation (ZHENG and YAO, 1993; SUN et al, 1994; ZHANG et al, 2001)

\begin{tabular}{cccccc}
\hline No. & Thickness $/ \mathrm{km}$ & $v_{\mathrm{P}} / \mathrm{km} \cdot \mathrm{s}^{-1}$ & $v_{\mathrm{S}} / \mathrm{km} \cdot \mathrm{s}^{-1}$ & ${\text { Density } / \mathrm{g} \cdot \mathrm{cm}^{-3}}$ Viscosity $/$ Pa.s $^{-3.3}$ & $1.0 \times 10^{30}$ \\
\hline 1 & 1.6 & 3.0 & 1.8 & 2.8 & $1.0 \times 10^{30}$ \\
2 & 2.7 & 4.7 & 3.6 & 2.8 & $1.0 \times 10^{30}$ \\
3 & 5.0 & 6.3 & 3.5 & 2.8 & $1.0 \times 10^{30}$ \\
4 & 8.7 & 6.10 & 3.6 & 2.8 & $7.1 \times 10^{18}$ \\
6 & 5.0 & 6.30 & 3.8 & 2.8 & $7.1 \times 10^{18}$ \\
7 & 8.0 & 6.70 & 3.86 & 3.0 & $7.1 \times 10^{18}$ \\
8 & 5.0 & 7.00 & 4.8 & 3.3 & $2.1 \times 10^{19}$ \\
\hline
\end{tabular}




\section{Methodology}

\subsection{Coulomb failure stress change}

According to Coulomb failure criteria, shear fracture occurs on the fault when the shear stress reaches the frictional strength. We define the Coulomb failure stress change $\Delta \sigma_{f}$ as (Harris, 1998;

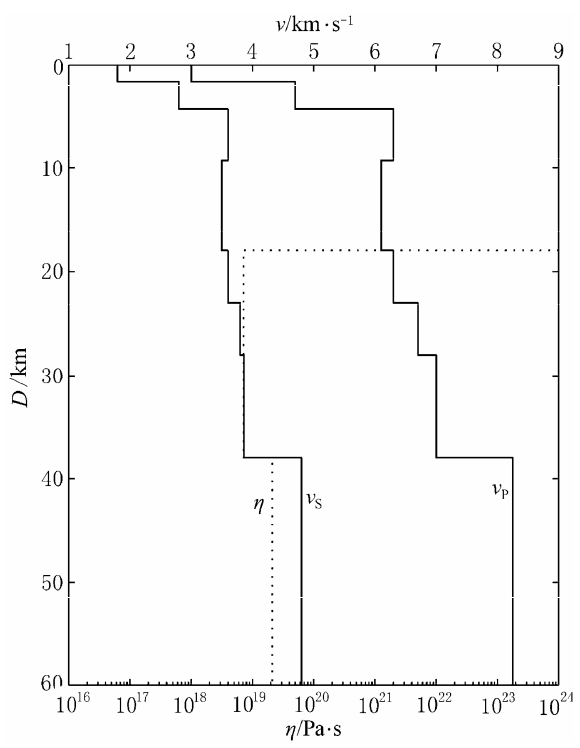

Figure 2 Crustal velocity and viscous structure model in Tangshan earthquake focal area

Stein, 1999):

$$
\Delta \sigma_{\mathrm{f}}=\Delta \tau_{\mathrm{s}}+c\left(\Delta \sigma_{\mathrm{n}}+\Delta p\right)
$$

Here, $c$ is friction coefficient with the value of $0.6 \sim 0.8$ for most rocks. $\Delta \tau_{\mathrm{s}}$ is the shear stress along the slip direction on the fault; $\Delta \sigma_{\mathrm{n}}$ and $\Delta p$ are normal stress on fault plane and the change of the pore pressure in the crust respectively (positive for tension). Hence, Coulomb failure stress change is the integrated effects of shear stress and normal stress on fault plane and fluid pore pressure. If $\Delta \sigma_{f}$ $>0$, the stress change encourages the occurrence of subsequent earthquakes, otherwise, discourages the occurrence of earthquakes.

In this study, by using the crustal model and seismic source model discussed above, the stress change of specified point is the summation of stress changes generated by each dislocation source in Maxwell visco-elastic medium by using program developed by ZENG (2001). The aftershock focal mechanisms are needed to study whether Tangshan mainshock and two large aftershocks encourage the occurrence of the following aftershocks. Firstly, we calculate the stress change tensor near the seismic source by using Zeng's method (ZENG, 2001), then stack with the local the tectonic stress tensor (Assuming pressure principal stress direction is $\mathrm{N} 60^{\circ} \mathrm{E}$ and extensional principal stress direction is $\mathrm{S} 30^{\circ} \mathrm{E}$ with the value of $10 \mathrm{MPa}, \mathrm{XU}$ and WANG, 1986) to achieve the total stress tensor at specific point, by which we calculate the two conjugate nodal planes with maximum shear stress. Choose the one that has the minimum angle with the fault plane of Tangshan mainshock as the fault plane of aftershock at the study point, and assuming that the direction of the maximum shear stress of the complete stress tensor at the study point on the fault surface is its slip direction; we get the rake angle of fault plane. Then the Coulomb failure stress change can be calculated by projecting the stress change tensor caused by co-seismic rupture and the underground visco-elastic relaxation onto this fault surface and its slip direction as in equation (1).

\subsection{Modification of the neighbor pore pressure and elastic constant of the earthquake fault surface}

Many previous studies attempted to cover the influence of the pore fluid pressure in the fixed apparent coefficient of the friction (King et al, 1994). In our study, we consider that the pore fluid pressure and the elastic constant at the seismic source are different from those of the surrounding medium. In Maxwell body study, viscous and elastic effects obey their own constitutive law and can be calculated separately. Within the neighbor of the seismic fault surface, we can revise the 
stress change caused by seismic rupture and visco-elastic relaxation by using the interactive relationship between elastic medium and fluid pore pressure.

The relation between stress and strain in elastic medium can be expressed as

$$
\varepsilon_{i j}=\frac{1}{2 \mu}\left[\sigma_{i j}-\frac{\lambda}{3 \lambda+2 \mu} \sigma_{k k} \delta_{i j}\right]
$$

among which $\varepsilon$ refers to the strain, $\sigma$ to stress, $\lambda$ and $\mu$ to Lamé constant, $\mu$ also called shear modulus, $\delta_{i j}$ to Kronecker $\delta, \varepsilon_{i j}=1, i=j ; \varepsilon_{i j}=0, i \neq j$.

Equation (2) can be converted as follows.

$$
\begin{aligned}
2\left(\varepsilon_{11}+\varepsilon_{22}\right) & =\frac{1}{\mu}\left[\sigma_{11}+\sigma_{22}-\frac{2 \lambda}{3 \lambda+2 \mu} \sigma_{k k}\right]=\frac{1}{\mu}\left[\sigma_{11}+\sigma_{22}-\frac{2 \lambda}{\lambda+\frac{2 \mu}{3}} \frac{\sigma_{k k}}{3}\right] \\
& =\frac{1}{\mu}\left[\sigma_{11}+\sigma_{22}-\frac{2 \lambda}{K} \frac{\sigma_{k k}}{3}\right]=\frac{1}{\mu}\left[\frac{\lambda+2 \mu}{K} \frac{\sigma_{k k}}{3}-\sigma_{33}\right]
\end{aligned}
$$

where $K$ is the body modulus. We assume that directions 1 and 2 indicate the two orthogonal directions on the fault plane, and direction 3 indicates the direction vertical to the fault plane. According to the relation between the strains and stresses of the fault zone and its surrounding area given by Rice (1992), the strains in the two directions on a fault plane are the same as those in the surrounding area, i. e., $\varepsilon_{11}=\mathcal{E}^{\prime}{ }_{11}, \varepsilon_{22}=\mathcal{E}_{22}^{\prime}$; the normal stress vertical to the fault plane in the focal area is the same as that in the surrounding area, i. e., $\sigma_{33}=\sigma_{33}^{\prime}$ (the stress, strain, elastic constant and Lamé constant on the fault plane are represented respectively by $\sigma^{\prime}, \varepsilon^{\prime}, K^{\prime}, \mu^{\prime}$ and $\lambda^{\prime}$, while those in the surrounding area are represented respectively by $\sigma, \varepsilon, K, \mu$ and $\lambda$, and the same is applicable hereafter). Thus, we obtain

$$
\frac{\sigma_{k k}^{\prime}}{3}=\frac{K^{\prime}}{\lambda^{\prime}+2 \mu^{\prime}}\left[\frac{\mu^{\prime}}{\mu} \frac{(\lambda+2 \mu)}{K} \frac{\sigma_{k k}}{3}+\frac{\mu-\mu^{\prime}}{\mu} \sigma_{33}\right]
$$

And the relation between the pore pressure change and the mean principal stress (Rice, 1992) is

$$
\Delta p^{\prime}=-B^{\prime} \frac{\Delta \sigma_{k k}^{\prime}}{3}
$$

Where $\Delta p^{\prime}$ is the pore fluid pressure change near the fault plane, and $B^{\prime}$ is the Skempton constant near the fault plane. Introducing equation (4) into equation (5), we get

$$
\Delta p^{\prime}=-B^{\prime} \frac{K^{\prime}}{\lambda^{\prime}+2 \mu^{\prime}}\left[\frac{\mu^{\prime}}{\mu} \frac{(\lambda+2 \mu)}{K} \frac{\Delta \sigma_{k k}}{3}+\frac{\mu-\mu^{\prime}}{\mu} \Delta \sigma_{33}\right]
$$

where $\Delta \sigma_{k k}$ is the sum of diagonal elements of the stress change tensor, $\Delta \sigma_{33}$ is the normal stress change on the fault plane. The equation demonstrates that the pore pressure change depends on the changes of the mean stress and the stress vertical to the fault plane.

According to the relation among the velocity of the $\mathrm{S}$ wave $v_{\mathrm{S}}$, elastic constant $\mu$ and density $\rho$, we get

$$
\frac{v_{\mathrm{S}}^{2}-v_{\mathrm{S}}^{\prime 2}}{v_{\mathrm{S}}^{2}}=\frac{\rho^{\prime} \mu-\rho \mu^{\prime}}{\rho^{\prime} \mu}
$$


where $v_{\mathrm{S}}$ and $\rho$ are the $\mathrm{S}$ wave velocity and density inside the fault plane, and $v_{\mathrm{S}}{ }^{\prime}$ and $\rho^{\prime}$ are the $\mathrm{S}$ wave velocity and density outside the fault plane.

If the density variation of the focal area and the surrounding crustal medium is not large, then we get

$$
\frac{\mu-\mu^{\prime}}{\mu}=\frac{v_{\mathrm{S}}^{2}-v_{\mathrm{S}}^{\prime 2}}{v_{\mathrm{S}}^{2}} \quad \frac{\mu^{\prime}}{\mu}=\left(\frac{v_{\mathrm{S}}^{\prime}}{v_{\mathrm{S}}}\right)^{2}
$$

We estimated the possible values of the elastic constant of the fault zone by the variation of the seismic wave velocity. And as for the study of the inner structure of the fault zone, the trapped wave study will provide more constraints on the elastic constant in the focal zone (LI et al, 1990, 1994). LI et al (1990) developed the failure density and the $\mathrm{S}$ wave velocity model of the Orovile fault zone in California from body wave travel time modeling. Their result shows that the $\mathrm{S}$ wave velocity in the fault zone is slower than that in the surrounding crust by $50 \%$, and the crack density in the focal area seems higher than that in the surrounding area. LI et al (1994) pointed out, in a further study, that the S wave velocity in the fault zone was approximately $50 \% \sim 70 \%$ of that in the surrounding area. We adopted the upper limit for the sake of assurance. So from equation (8) we derived that the rigidity ratio $\mu^{\prime} / \mu$ was 0.49 , and the rigidity decreased in the fault area $\left(\mu-\mu^{\prime}\right) / \mu$ was 0.51 .

Supposing that the surrounding crust is Poisson body, $K^{\prime}=K=5 \mu / 3$, then

$$
\lambda^{\prime}+2 \mu^{\prime}=K^{\prime}+\frac{4 \mu^{\prime}}{3}=\left(\frac{5}{3}+\frac{4}{3} \frac{\mu^{\prime}}{\mu}\right) \mu
$$

Thus,

$$
\frac{K^{\prime}}{\lambda^{\prime}+2 \mu^{\prime}}=\frac{K}{\lambda^{\prime}+2 \mu^{\prime}}=\frac{5}{3} \frac{\mu}{\lambda^{\prime}+2 \mu^{\prime}}=\frac{5}{5+4 \frac{\mu^{\prime}}{\mu}}=0.7184
$$

And as for area far away from the fault

$$
\frac{K}{\lambda+2 \mu}=\frac{\lambda+\frac{2}{3} \mu}{\lambda+2 \mu}=\frac{\frac{5}{3} \mu}{3 \mu}=\frac{5}{9}
$$

By introducing the parameters obtained into equation (6), considering the above supposition that the $\mathrm{S}$ wave velocity is $70 \%$ of that in the surrounding area, we get

$$
\Delta p^{\prime}=-B^{\prime}\left(0.6336 \frac{\sigma_{k k}}{3}+0.3664 \Delta \sigma_{33}\right)
$$

Thus we get the relation between the change of the pore fluid pressure in the focal area and the stress change caused by the earthquake. And the Coulomb failure stress change surrounding the seismic fault can be calculated by the following equation derived from equation (1),

$$
\Delta \sigma_{\mathrm{f}}^{\prime}=\Delta \tau+c^{\prime}\left[\Delta \sigma_{33}-B^{\prime}\left(0.6336 \frac{\sigma_{k k}}{3}+0.3664 \Delta \sigma_{33}\right)\right]
$$

According to Cocco and Rice (2002), we take $B^{\prime}=0.47, c^{\prime}=0.75$, which corresponds to apparent coefficient of the friction $c$ as 0.4 (King et al, 1994). These values will be adopted in the following calculation. 
The Coulomb failure stress change within $10 \mathrm{~km}$ from the fault plane is calculated by equation (13), and that far away from the fault is calculated in the traditional method.

\section{Simulation result}

\subsection{Triggering effect of Tangshan mainshock on two large aftershocks}

According to the source parameters listed in Table 1 and the crust structure parameters listed in Table 2, and calculation method of Coulomb failure stress change stated above, we calculated Coulomb failure stress change at the location of Luanxian earthquake occurred 17 hours later caused by Tangshan mainshock, and that at the location of Ninghe earthquake occurred on November 15 caused by Tangshan mainshock and Luanxian aftershock, as shown in Figure 3. It is obvious that the occurrence of Luanxian earthquake is driven by Coulomb failure stress change with the value of $0.05 \sim 0.2 \mathrm{MPa}$ caused by Tangshan mainshock. The occurrence of Ninghe earthquake is driven by Coulomb failure stress change of $0.2 \mathrm{MPa}$ caused by Tangshan mainshock and Luanxian aftershock. This is consistent with the results of the previous study that mainshock triggered Luanxian earthquake (WAN et al, 2000; Robinson and ZHOU, 2005) and Tangshan mainshock and Luanxian aftershock triggered Ninghe earthquake (Robinson and ZHOU, 2005). However, result in his study has considered the visco-elastic relaxation effect and the vertical inhomogeneous medium structure and the parameters chosen are more practical, which is, therefore, more consistent with actual underground situation. As for the stress triggering of Luanxian earthquake by Tangshan mainshock, viscous relaxation effect is not obvious because the time interval is short, but in that of Ninghe earthquake caused by Tangshan mainshock and Luanxian aftershock, which has a time interval of 110 days, comparing the result of elastic stress triggering (White dotted lines in Figure 3b), most absolute Coulomb failure stress changes increase in numerical value, though not very obviously in the Figure $3 b$.

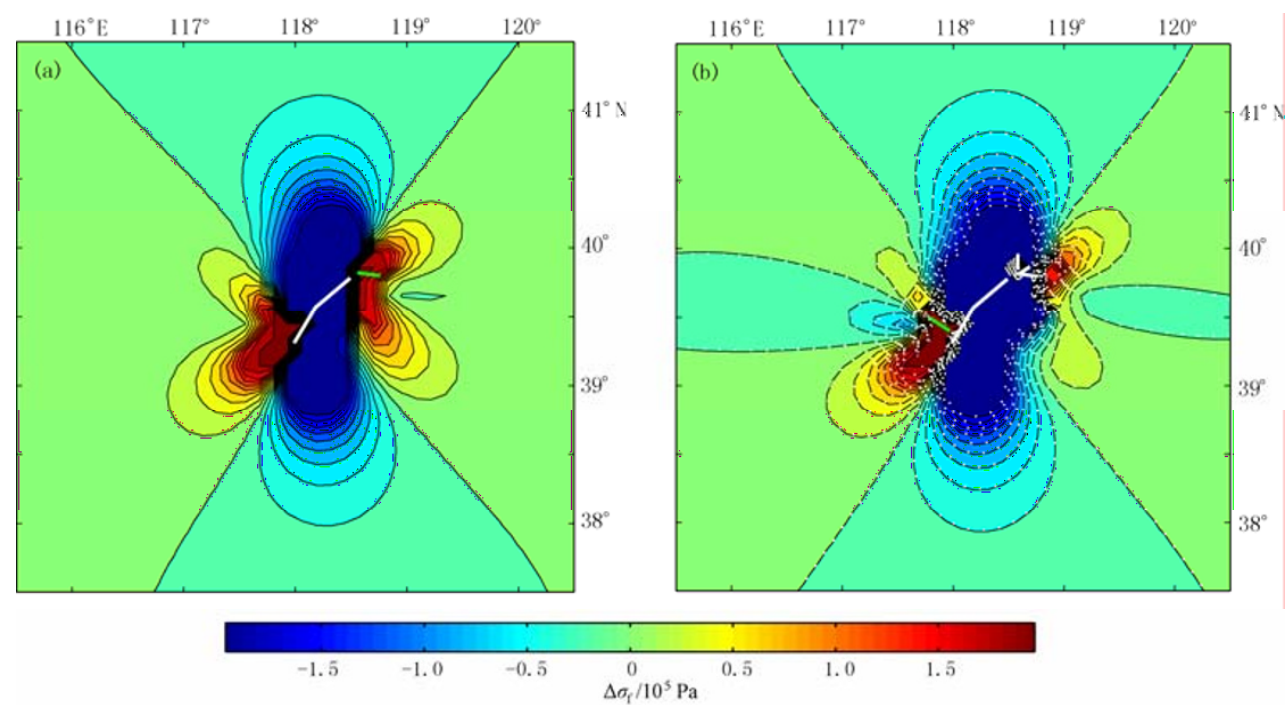

Figure 3 Coulomb failure stress change projected on Luanxian aftershock's (a) and Ninghe aftershock's (b) fault plane and slip direction generated by the previous earthquakes

White thick lines stand for rupture traces of Tangshan mainshock. Green thick ones are rupture traces of Luanxian aftershock (a) and Ninghe aftershock (b) respectively. Dash white lines stand for the result calculated from elastic model 


\subsection{Triggering effect on follow -up aftershocks by Tangshan mainshock and two large aftershocks}

In order to study the influence on follow-up aftershocks produced by Tangshan mainshock and two large aftershocks, we divided the period from the occurrence time of Ninghe earthquake to January, 2006 into 10 intervals, with about 2.8 years in each time interval and compared the Coulomb failure stress change in each interval with the corresponding seismicity. And the simulation results are shown in Figure 4.

In Figure 4, we can see that most of absolute Coulomb failure stress changes increase gradually with time lapses and is more obvious in the initial 10 years after the earthquakes, then attenuating gradually with time. This is in accordance with the relaxation process of visco-elastic medium of Maxwell body. Particular attention should be paid to the fact that the positive Coulomb failure stress change area in south-east extension direction of Ninghe earthquake is small at the initial intervals after the earthquakes and then becomes larger with the time lapses, turning the shadow zone of Coulomb failure stress change into triggering one eventually. This phenomenon has been verified in the research by Freed and LIN (2001) and ZENG (2001).

There occurred a large number of aftershocks in northeast, southeast and southwest petal of our calculated stress triggering region. But only a few aftershocks occurred in the northwest petal, especially at the final intervals. There are a few aftershocks occurred in shadow zone, especially in the east and south parts of shadow zone. The aftershocks occurred in east shadow zone might be related to the inaccuracy of fault model, which is to be revised by using more accurate rupture model of this earthquake sequence. The seismicity in other shadow zones is much lower than that of stress triggering zone. In addition, most of the absolute Coulomb failure stress change increase gradually with time while seismicity of aftershocks comes down gradually according to Omori law, but the spatial distribution of aftershocks fits the petal of Coulomb failure stress change. Generally speaking, $95 \%$ of the aftershocks occurred in the positive Coulomb failure stress change region, which illuminating that our model is basically correspond to the actual incidence rate of aftershocks.

\section{Discussion and conclusions}

We have calculated the influence on Luanxian aftershocks caused by Tangshan mainshock and the influence on Ninghe aftershock caused by Tangshan mainshock and Luanxian aftershock. Our results show that the two largest aftershocks both occurred in the region with positive Coulomb failure stress change caused by the previous earthquakes. This shows that the locations of the large aftershocks could be predicted if the Coulomb failure stress change around Tangshan earthquake region could be calculated immediately after the mainshock. Yet the key point in calculation is the rapid determination of the fault orientation and rupture distribution of the mainshock, which is likely to be realized with the widely deploying of the modern digital seismic network at present. However, the calculation also needs the details of the fault on which large aftershocks could occur. For Anatolia fault, after a large earthquake occurred, the future earthquake focal mechanism can be reasonably assumed (Nalbant et al, 1998). As for the situation of the Tangshan earthquake sequence, the focal mechanism of Ninghe earthquake could be achieved by geological fault survey, but that of Luanxian aftershocks is unknown though its mechanism is consistent with geological structure.

According to stress direction in Tangshan earthquake region by XU and WANG (1986) and the assumption of the tectonic stress value as $10 \mathrm{MPa}$, we calculated the Coulomb failure stress change generated by Tangshan mainshock and two largest aftershocks by using layered visco-elastic model and compared it with the aftershocks locations at each interval. The results 
show that $95 \%$ of the aftershocks occurred in the region with positive Coulomb failure stress change, indicating that the future development trend of the aftershocks could be predicted if the rupture distribution and mechanisms of the mainshock and large aftershocks be rapidly determined.
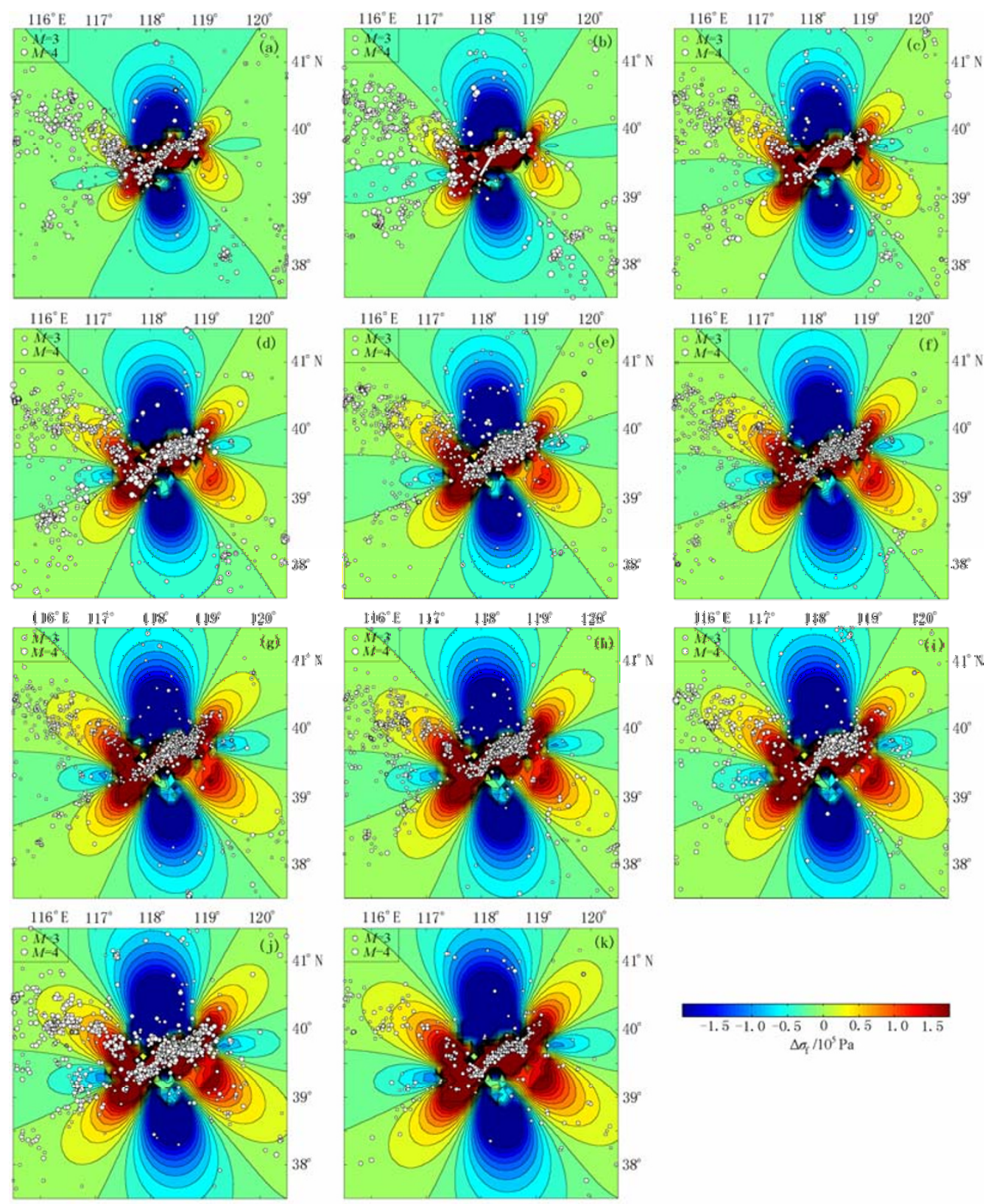

Figure 4 Coulomb failure stress change evolution generated by Tanshan mainshock and its two large aftershocks and corresponding aftershocks at different intervals, 2.8 years for each interval 'o' stands for aftershocks at each interval. White lines are rupture traces of mainshock and two large aftershocks. (a) Tangshan mainshock-1979.379; (b) 1979.379 1982.179; (c) 1982.179 1984.979; (d) 1984.979 1987.779; (e) 1987.779 1990.580; (f) 1990.580 1993.380; (g) 1993.380 1996.180; (h) 1996.180 1998.981; (i) 1998.981 2001.781; (j) 2001.781 2004.581; (k) 2004.581 2006.100 
In the calculation of triggering effect on aftershocks generated by Tangshan mainshock and two large aftershocks, we assumed that tectonic stress value is $10 \mathrm{MPa}$. If this value is changed, the pattern of Coulomb failure stress change would be changed a certain degree near the fault plane of main shock, but the pattern of Coulomb failure stress change would not be changed far away from the fault. This is because the mainshock has little effect on direction of the stress field far away from the fault.

Considering the uncertainty of the fault rupture zone, we assumed a neighbor area of $10 \mathrm{~km}$ around the fault plane as one where pore fluid pressure and medium elastic constant would be changed by the rupture of fault, and the different distance of this value would not change the pattern of Coulomb failure stress change. In this study, we researched Coulomb failure stress change by considering a variety of known factors, yielding a triggering rate of $95 \%$ for aftershocks. Our study provided a possible and significant reference to the seismic stress triggering study from a comprehensive point of view.

Acknowledgements Thanks are due to Prof. WU Zhong-liang for his coaching to first author in the physics of seismic source and seismic dynamics. The suggestions from anonymous referees were of significant help in improving the manuscript.

\section{References}

Ben-Zion Y, Rice J R, Dmowska R. 1993. Interaction of the San Andreas fault creeping segment with adjacent great rupture zones and earthquake recurrence at Parkfield [J]. J Geophys Res, 98: 2 135-2 144.

Butler R, Stewart G S, Kanamori H. 1979. The July 27, 1976 Tangshan, China earthquake: A complex sequence of intraplate events [J]. Bull Seism Soc Amer, 69: 207-220.

Chen W and Nabelek J. 1988. Seismogenic strike-slip faulting and the development of the North China Basin [J]. Tectonics, 7: 975-989.

CHEN Yun-tai, HUANG Li-ren, LIN Bang-hui, et al. 1979. A dislocation model of the Tangshan earthquake of 1976 from the inversion of geodetic data [J]. Chinese J Geophys, 22(3): 201-217 (in Chinese).

Cocco M and Rice J R. 2002. Pore pressure and poroelasticity effects in Coulomb stress analysis of earthquake interactions [J]. J Geophys Res, 107(B2): 2030, doi:10.1029/2000JB000138

Das S and Scholz C. 1981. Off-fault aftershock clusters caused by shear stress increase? [J] Bull Seism Soc Amer, 71: $1669-1675$.

Freed A M and Lin J. 2001. Delayed triggering of the 1999 Hector Mine earthquake by viscoelastic stress transfer [J]. Nature, 411: 180-183.

Harris R A. 1998. Introduction to special section: Stress triggers, stress shadows, and implications for seismic hazard [J]. J Geophys Res, 103: $24347-24358$.

Huang B and Yeh Y T. 1997. The fault ruptures of the 1976 Tanghsan earthquake sequence inferred from coseismic crustal deformation [J]. Bull Seism Soc Amer, 87: 1 046-1 057.

Kikuchi M and Kanamori H. 1986. Inversion of complex body waves II [J]. Phys Earth Planet Interi, 43: 205-222.

King G C P, Stein R S, Lin J. 1994. Static stress changes and the triggering of earthquakes [J]. Bull Seism Soc Amer, 84: $935-953$.

Li Y G, Leary P C, Aki K, et al. 1990. Seismic trapped modes in the Oroville and San Andreas fault zones [J]. Science, 249: $763-766$.

Li Y G, Aki K, Vidale J, et al. 1994. Fine structure of the Landers fault zone: Segmentation and the rupture process [J]. Science, 265: 367-380, doi: 10.1126/science.265.5170.367.

LI Zhi-cai, XU Cai-jun, ZHAO Shao-rong, et al 2005. The postseismic deformation analysis based on crustal layering due to Tangshan earthquake fault [J]. Progress in Geophysics, 20(4): 961-968 (in Chinese).

LIU Gui-ping and FU Zheng-xiang. 2000. Regional seismicity triggered by the $M_{\mathrm{S}}=7.8$ Tangshan event on July 28,1976 and the static stress field change [J]. Acta Seismologica Sinica, 13(1): 19-28.

LIU Chang-quan and JIA Shi-xu. 1986. Structural property of the crust and the upper mantle in the Tangshan earthquake region: A method of computing body wave theoretical seismologram and the result of analysis of 2-D inhomogeneous media [J]. Acta Seismologica Sinica, 8(4): 341-353 (in Chinese).

Ma K and Chan C. 2005. Response of seismicity of Coulomb stress triggers and shallows of the $1999 M_{\mathrm{W}}=7.6$ Chi-Chi, Taiwan, earthquake [J]. J Geophys Res, 110: B05S19, doi: 10.1029/2004JB003389.

Nalbant S S, Hubert A, King G C P. 1998. Stress coupling between earthquakes in northwest Turkey and the north Aegean Sea [J]. $J$ Geophys Res, 103: 24 469-24 486.

Nabelek J, Chen W P, Ye H. 1987. The Tangshan earthquake sequence and its implications for the evolution of the North China basin [J]. J Geophys Res, 92: 12 615-12 628.

Nur A and Booker J R. 1972. Aftershocks caused by pore fluid flow? [J] Science, 175: 885-887.

Nur A and Mavko G. 1974. Postseismic viscoelastic rebound [J]. Science, 183: 204-206. 
Okada Y. 1992. Internal deformation due to shear and tensile faults in a half-space [J]. Bull Seism Soc Amer, 82: $1018-1$ 040.

Piombo A, Martinelli G, Dragoni M. 2005. Post-seismic fluid flow and Coulomb stress changes in a poroelastic medium [J]. Geophys $J$ Int, 162: 507-515.

Pollitz F F. 1992. Postseismic relaxation theory on the spherical earth [J]. Bull Seism Soc Amer, 82: 422-453.

Pollitz F F and Sacks I S. 1997. The 1995 Kobe, Japan, earthquake: A long-delayed aftershock of the offshore 1944 Tonankai and 1946 Nankaido earthquakes [J]. Bull Seism Soc Amer, 87: 1-10.

Pollitz F F and Schwartz D P. 2008. Probabilistic seismic hazard in the San Francisco Bay area based on a simplified viscoelastic cycle model of fault interactions [J]. J Geophys Res, 113: B05409, doi:10.1029/2007JB005227.

QIU Qun. 1976. On the background and seismic activity of the M7.8 Tangshan earthquake, Hebei Province of July 28, 1976 [J]. Chinese J Geophys, 19(4): 259-269 (in Chinese).

Rice J R. 1992. Fault stress states, pore pressure distributions and the weakness of the San Andreas fault [C]//Evans B and T-F Wong. Fault Mechanics and Transport Properties of Rock. San Diego, Calif.: Academic Press: 475-503.

Robinson R and Zhou S. 2005. Stress interactions within the Tangshan, China, earthquake sequence of 1976 [J]. Bull Seism Soc Amer, 95(6): 2 501-2 505.

Rydelek P A and Sacks I S. 1990. Asthenospheric viscosity and stress diffusion: A mechanism to explain correlated earthquakes and surface deformation in NE Japan [J]. Geophys J Int, 100: 39-58.

Seeber L, Ambruster J G, Kim W Y, et al. 1998. The 1994 Cacoosing Valley earthquakes near Reading, Pennsylvania: A shollow rupture triggered by quarry unloading [J]. J Geophys Res, 103: 24 505-24 521.

Shedlock K, Baranowski J, Xiao W, et al. 1987. The Tangshan aftershock sequence [J]. J Geophys Res, 92: 2 791-2 803.

SHEN Zheng-kang, WAN Yong-ge, GAN Wei-jun, et al. 2003. Viscoelastic triggering between large earthquakes along the east Kunlun fault system [J]. Chinese J Geophys, 46(6): 1 125-1 138.

Stein R S. 1999. The role of stress transfer in earthquake occurrence [J]. Nature, 402: 605-609.

SUN Xun-ying, LIU Ji-yang, WANG Ren. 1994. The simulation of coseismic and postseismic crustal deformation due to Tanshan earthquake in 1976 [J]. Chinese J Geophys, 37(1): 45-55 (in Chinese).

Troise C, De Natale G, Pingue F, et al. 1998. Evidence for static stress interaction among earthquakes in south-central Apennines (Italy) [J]. Geophys J Int, 134: 809-817.

Toda S, Stein R S, Reasenberg P A, et al. 1998. Stress transferred by the $1995 M_{\mathrm{W}}=6.9$ Kobe, Japan, shock: Effect on aftershocks and future earthquake probabilities [J]. J Geophys Res, 103: 24 543-24 565.

US Geological Survey, Southern California Earthquake Center, California Division of Mines and Geology. 2000. Preliminary report on the 16 October 1999 M7.1 Hector Mine, California, earthquake [J]. Seism Res Lett, 71: 11-23.

Wald D J and Heaton T H. 1994. Spatial and temporal distribution of slip for the 1992 Landers, California earthquake [J]. Bull Seism Soc Amer, 84: 668-691.

WAN Yong-ge, WU Zhong-liang, ZHOU Gong-wei, et al. 2000. "Stress triggering" between different rupture events in several earthquakes [J]. Acta Seismologica Sinica, 13(6): 607-615.

WAN Yong-ge, SHEN Zheng-kang, DIAO Gui-ling, et al. 2008. An algorithm of fault parameter determination using distribution of small earthquakes and parameters of regional stress field and its application to Tangshan earthquake sequence [J]. Chinese J Geophys, 51(3): 569-583 (in Chinese).

WAN Yong-ge, SHEN Zheng-kang, SHANG Dan. 2007a. Study on the triggering effect of the October, 2005 Pakistan $M_{\mathrm{W}} 7.6$ earthquake on its application [J]. Earthquake Research in China, 21(1): 33-42.

WAN Yong-ge, SHEN Zheng-kang, ZENG Yue-hua, et al. 2007b. Evolution of cumulative Coulomb failure stress in northeastern Qinghai-Xizang (Tibetan) Plateau and its effect on large earthquake occurrence [J]. Acta Seismologica Sinica, 20(2): 117-132.

Xie X B and Yao Z X. 1991. The faulting process of Tangshan earthquake inverted simultaneously from teleseismic waveforms and geodetic deformation [J]. Phys Earth Planet Interi, 66: 265-277.

XU Zhong-huai. 1985. Mean stress field in Tangshan aftershock area obtained form focal mechanism data by fitting slip direction [J]. Acta Seismologica Sinica, 7(4): 359-362 (in Chinese).

XU Zhong-huai and WANG Su-yun. 1986. A possible change in stress field orientation due to the 1976 Tangshan earthquake [J]. Pure Appl Geophys, 51: 139-154.

YU Xiang-wei, CHEN Yun-tai, WANG Pei-de. 2003. Three dimensional P wave velocity structure in Beijing-Tianjin-Tangshan area [J]. Acta Seismologica Sinica, 25(1): 1-14 (in Chinese).

ZENG Rong-sheng, ZHANG Shao-quan, ZHOU Hai-nan, et al. 1985. Crustal structure of Tangshan epicentral region and its relation to the seismogenic process of a continental earthquake[J]. Acta Seismolgica Sinica, 7(2): 125-142 (in Chinese).

Zeng Y. 2001. Viscoelastic stress-triggering of the 1999 Hector Mine earthquake by the 1992 Landers earthquake [J]. Geophys Res Lett, 28: $3007-3010$.

ZHANG Xue-min, SU Pei-yi, DIAO Gui-ling, et al. 2001. Study on the P and S wave velocity structure under Tangshan region with digital earthquake record [J]. North China Earthquake Science, 19(1): 10-17 (in Chinese).

ZHANG Zhi-li, LI Qin-zu, GU Ji-cheng, et al. 1980. The fracture processes of the Tangshan earthquake and its mechanical analysis [J]. Acta Seismologica Sinica, 2(2): 111-129 (in Chinese).

ZHANG Zu-sheng. 1982. Geodetic deformation background and the analysis of deformation anomalies [C]//State Seismological Bureau. The 1976 Tangshan Earthquake. Beijing: Seismological Press: 131-170 (in Chinese).

ZHENG Tian-yu and YAO Zhen-xing. 1993. Source process study of the Tangshan earthquake using the near-field records [J]. Chinese $J$ Geophys, 36(2): 174-184 (in Chinese).

ZHOU Hui-lan. 1985. Some characteristics of source processes of large shallow strike-slip earthquakes [J]. Chinese J Geophys, 28(6): 579-587 (in Chinese). 